\title{
Bacillus velezensis is a later heterotypic synonym of Bacillus amyloliquefaciens
}

Correspondence

Fwu-Ling Lee

fll@firdi.org.tw

\author{
Li-Ting Wang, Fwu-Ling Lee, Chun-Ju Tai and Hsiao-Ping Kuo
}

Bioresource Collection and Research Center, Food Industry Research and Development Institute, PO Box 246, Hsinchu 30099, Taiwan, ROC

\begin{abstract}
Strain BCRC 14193, isolated from soil, shared more than $99 \% 16 \mathrm{~S}$ rRNA gene sequence similarity with Bacillus amyloliquefaciens BCRC $11601^{\top}$ and Bacillus velezensis BCRC $17467^{\top}$. This strain was previously identified as $B$. amyloliquefaciens, based on DNA-DNA hybridization, but its DNA relatedness value with $B$. velezensis $B C R C 17467^{\top}$ was $89 \%$. To investigate the relatedness of strain BCRC 14193, B. amyloliquefaciens and $B$. velezensis, the partial sequence of the gene encoding the subunit B protein of DNA gyrase ( $g y r B)$ was determined. B. velezensis BCRC $17467^{\top}$ shared high gyrB gene sequence similarity with $B$. amyloliquefaciens BCRC $14193(98.4 \%)$ and all of the $B$. amyloliquefaciens strains available (95.5-95.6\%). DNA-DNA hybridization experiments revealed high relatedness values between $B$. velezensis BCRC $17467^{\top}$ and $B$. amyloliquefaciens BCRC $11601^{\top}(74 \%)$ and the $B$. amyloliquefaciens reference strains (74-89\%). Based on these data and the lack of phenotypic distinctive characteristics, we propose Bacillus velezensis as a later heterotypic synonym of Bacillus amyloliquefaciens.
\end{abstract}

Bacillus velezensis, isolated from the mouth of the river Vélez in Málaga (southern Spain), has been described recently by Ruiz-García et al. (2005). The type strain BCRC $17467^{\mathrm{T}}\left(\mathrm{CR}-502^{\mathrm{T}}=\mathrm{LMG} 22478^{\mathrm{T}}\right)$ and strain CR-14b had identical 16S rRNA gene sequences and the topology of the phylogenetic tree confirmed that they were members of the Bacillus subtilis group. The $16 \mathrm{~S}$ rRNA gene sequences of these strains shared $99 \%$ similarity with Bacillus subtilis subsp. subtilis (Nakamura et al., 1999), Bacillus amyloliquefaciens (Priest et al., 1987) and Bacillus vallismortis (Roberts et al., 1996), and 98\% similarity with Bacillus mojavensis (Roberts et al., 1994) and Bacillus atrophaeus (Nakamura, 1989). DNA-DNA hybridization analysis confirmed that B. velezensis BCRC $17467^{\mathrm{T}}$ and CR-14b show less than $20 \%$ relatedness with the species mentioned above. The two strains were characterized by their capacity to produce acids from glycogen, lactose, methyl $\alpha$-Dglycoside and raffinose, but not from turanose, and produce $\beta$-galactosidase (determined by ONPG reaction), but not arginine dihydrolase. Strain CR $-502^{\mathrm{T}}$ showed a specific fatty acid profile characterized mainly by its high $\mathrm{C}_{16: 0}$ content and the presence of $\mathrm{C}_{16: 1} \omega 11 \mathrm{c}$, iso- $\mathrm{C}_{13: 0}$, $\mathrm{C}_{14: 0}$ and iso- $\mathrm{C}_{17: 1} \omega 10 c$. Genomic and phenotypic data demonstrated that $B$. velezensis represents a novel species of Bacillus (Ruiz-García et al., 2005).

The GenBank/EMBL/DDBJ accession numbers for the 16S rRNA and gyrB gene sequences of Bacillus velezensis strain BCRC $17467^{\top}$ are EF433407 and D0903176.

Additional phylogenetic trees and fatty acid composition and phenotypic characteristic tables are available with the online version of this paper.
B. amyloliquefaciens, isolated from soil, was first proposed by Fukumoto (1943a, b). This taxon was not included in the Approved Lists of Bacterial Names (Skerman et al., 1980), but was later revived by Priest et al. (1987). B. amyloliquefaciens is responsible for much of the world production of $\alpha$-amylase and protease (Harwood, 1992). $B$. amyloliquefaciens is closely related to B. subtilis and there is a need to distinguish them in the enzyme industry to avoid confusion with B. subtilis, which differs metabolically and secretes different enzymes (Priest, 1977). B. amyloliquefaciens can be distinguished from $B$. subtilis by a few phenotypic traits and DNA similarity (Logan \& Berkeley, 1984; Nakamura, 1987; O’Donnell et al., 1980).

Strain BCRC 14193 was isolated from soil taken from Hsinchu, Taiwan. For the isolation of strain BCRC 14193, a $10 \mathrm{~g}$ soil sample was vortexed with $50 \mathrm{ml}$ sterile distilled water for $5 \mathrm{~min}$. Serial 50-fold dilutions were prepared and $100 \mu \mathrm{l}$ of the mixture was spread onto trypticase soy agar (TSA; Difco) at $30{ }^{\circ} \mathrm{C}$ for $24 \mathrm{~h}$ under aerobic conditions. Morphologically distinct single colonies that developed were picked up and restreaked onto fresh TSA at least twice before being considered pure. Pure strains were preserved at $-80{ }^{\circ} \mathrm{C}$ in trypticase soy broth or by lyophilization. Strain BCRC 14193 was identified as B. amyloliquefaciens, based mainly on DNA-DNA hybridization (77\%), in our previous study (Wang et al. 2007b). In addition to strain BCRC 14193, B. amyloliquefaciens strains BCRC $11601^{\mathrm{T}}$, BCRC 14711 and BCRC 17038 and other related taxa were selected for further comparative study. B. velezensis BCRC $17467^{\mathrm{T}}$ was also included in the study. All strains were 
cultivated in nutrient agar or broth (Difco) at $30{ }^{\circ} \mathrm{C}$ for $24 \mathrm{~h}$ under aerobic conditions.

Genomic DNA was isolated using the Qiagen Blood \& Cell Culture DNA kit. The 16S rRNA gene sequence was PCRamplified and sequenced using the MicroSeq Full Gene 16S rDNA Bacterial Identification kit (Applied Biosystems). The partial sequence of the gene encoding the subunit B protein of DNA gyrase (gyrB) was included in the phylogenetic analysis for comparative purposes. The gyrB gene was PCR-amplified and sequenced using a set of primers described by Wang et al. (2007b). Sequencing was performed using a 3730 DNA sequencer (Applied Biosystems and Hitachi). Sequence assembly was performed using the ABI PRISM DNA Sequencing Analysis software (PE Applied Biosystems). Sequence similarity was calculated and DNA sequences were translated using the Wisconsin Package version 10.1 (Accelrys). The sequences obtained in this study and from GenBank were aligned using the CLUSTAL_x program, version 1.8 (Thompson et al., 1997), and phylogenetic analysis including neighbourjoining, maximum-parsimony and maximum-likelihood trees of DNA and protein sequence alignments were performed with the PHYLIP computer program package (Felsenstein, 2002). Bootstrap analysis was made with 1000 replicates, except for maximum-likelihood, where only 100 replicates were generated. Tree figures were drawn with MEGA3 (Kumar et al., 2004). Phylogenetic analysis by the neighbour-joining (Fig. 1), maximum-parsimony and maximum-likelihood methods (see Supplementary Figs S1 and S2, available in IJSEM Online) produced similar trees, with the exception of minor differences in the tree topology of the basal branches.

The phylogenetic tree of the 16S rRNA gene sequences between positions 35 and 1431 (Escherichia coli K-12 numbering) showed that B. velezensis and B. amyloliquefaciens strains are more closely related to $B$. vallismortis (Fig. 1a). B. velezensis BCRC $17467^{\mathrm{T}}$ shared $99.9 \%$ similarity with B. vallismortis BCRC $17183^{\mathrm{T}}$ and $99.7 \%$ similarity with all of the $B$. amyloliquefaciens strains available (Table 1). Although strain BCRC 14193 is on the same branch as the B. velezensis type strain, all Bacillus species among this cluster showed more than $99 \% 16 \mathrm{~S}$ rRNA gene sequence identity, indicating that it is not sufficient to discriminate one species from another. Comparatively, the tree based on the gyrB gene sequences between positions 316 and 1480 (E. coli K-12 numbering) clearly showed that $B$. velezensis $\mathrm{BCRC} 17467^{\mathrm{T}}$ and the $B$. amyloliquefaciens strains investigated formed a phylogenetic grouping with $100 \%$ bootstrap support (Fig. 1b). B. velezensis $\mathrm{BCRC} 17467^{\mathrm{T}}$ shared $98.4 \%$ gyrB gene sequence similarity with $B$. amyloliquefaciens BCRC 14193 and $95.5-95.6 \%$ similarity with the other $B$. amyloliquefaciens strains, whereas the sequence similarities between $B$. velezensis and other members of the related cluster were less than $81 \%$. High sequence similarity of the $g y r B$ gene of $B$. velezensis BCRC $17467^{\mathrm{T}}$ and B. amyloliquefaciens BCRC 14193 meant that they yielded a branch with the $B$.
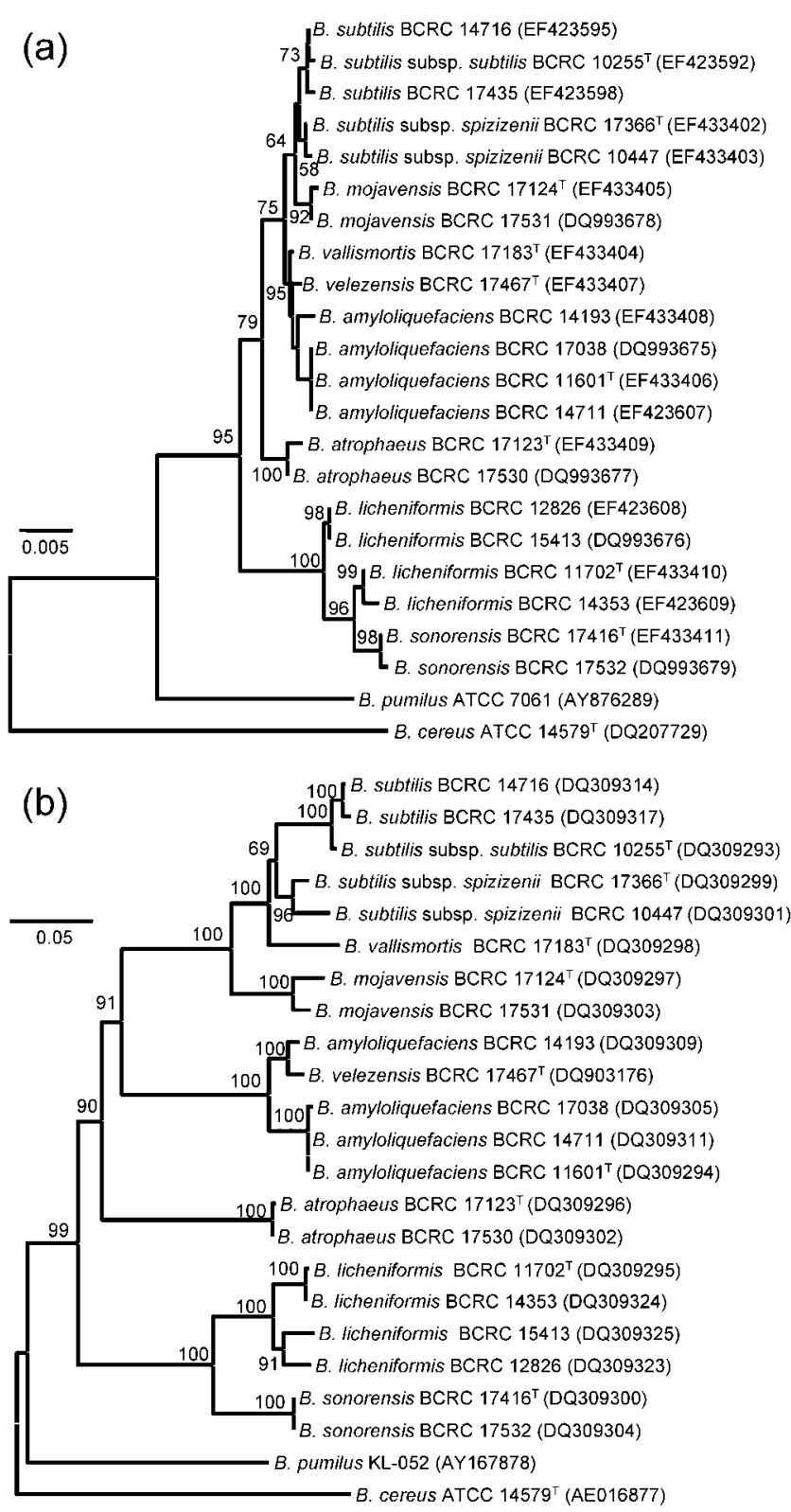

Fig. 1. Neighbour-joining phylogenetic trees based on $16 \mathrm{~S}$ rRNA (a) and gyrB (b) gene sequences of Bacillus strains. Genetic distances were computed by Kimura's two-parameter model. Only bootstrap percentages above $50 \%$ are shown. Bars, 0.005 (a) or 0.05 (b) substitutions per nucleotide position.

amyloliquefaciens strains. This tree topology can be observed in the B. licheniformis cluster group. B. licheniformis BCRC $11702^{\mathrm{T}}$ shared $99.8 \%$ similarity with $B$. licheniformis BCRC 14353 and 95.5-95.7\% similarity with the other B. licheniformis strains (BCRC $11702^{\mathrm{T}}$ and the $B$. licheniformis strains investigated showed high DNA-DNA relatedness values of 72-91\%). Phylogenetic analysis based on GyrB protein sequence trees led to the same overall conclusions (these trees are provided as Supplementary Figs S3-S5 in IJSEM Online). B. velezensis BCRC $17467^{\mathrm{T}}$ 
Table 1. Levels of gyrB and $16 \mathrm{~S}$ rRNA gene sequence similarity and DNA relatedness values between Bacillus strains

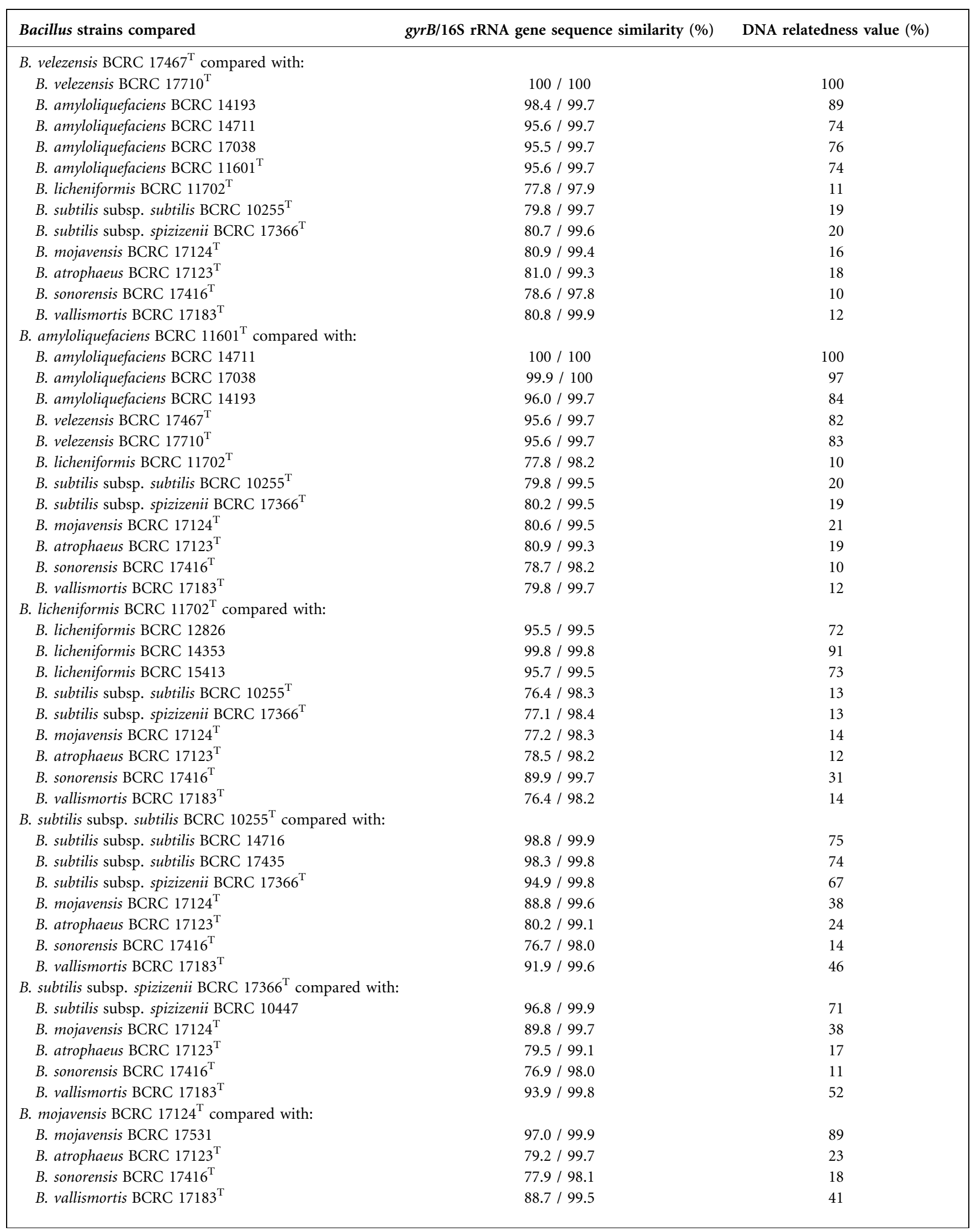


Table 1. cont.

\begin{tabular}{|c|c|c|}
\hline Bacillus strains compared & gyrB/16S rRNA gene sequence similarity (\%) & DNA relatedness value $(\%)$ \\
\hline \multicolumn{3}{|c|}{ B. atrophaeus $\mathrm{BCRC} 17123^{\mathrm{T}}$ compared with: } \\
\hline B. atrophaeus BCRC 17530 & $99.8 / 99.9$ & 90 \\
\hline B. sonorensis BCRC $17416^{\mathrm{T}}$ & $79.3 / 98.1$ & 15 \\
\hline B. vallismortis $\mathrm{BCRC} 17183^{\mathrm{T}}$ & $79.1 / 99.4$ & 21 \\
\hline \multicolumn{3}{|c|}{ B. sonorensis BCRC $17416^{\mathrm{T}}$ compared with: } \\
\hline B. sonorensis BCRC 17532 & $100 / 99.8$ & 92 \\
\hline B. vallismortis $\mathrm{BCRC} 17183^{\mathrm{T}}$ & $75.4 / 98.1$ & 13 \\
\hline
\end{tabular}

and the B. amyloliquefaciens strains investigated formed a phylogenetic grouping and are closely related to the group of B. atrophaeus.

DNA base composition and DNA relatedness values were determined as described previously (Tamaoka \& Komagata, 1984; Ezaki et al., 1989; Goris et al., 1998; Tai et al., 2006). DNA G+C contents of B. velezensis BCRC $17467^{\mathrm{T}}$ and $B$. amyloliquefaciens strains BCRC $11601^{\mathrm{T}}$, BCRC 14193 and BCRC 17038 were 45.7, 45.4, 45.9 and $45.2 \mathrm{~mol} \%$, respectively. These values were close to the value of 44-46 mol\% which was described for the strains of B. amyloliquefaciens (Priest et al., 1987). The relatedness of the genomic DNA of the strains tested is shown in Table 1. B. velezensis BCRC $17467^{\mathrm{T}}$ and B. amyloliquefaciens strains BCRC $11601^{\mathrm{T}}$, BCRC 14193, BCRC 14711 and BCRC 17038 showed high DNA-DNA relatedness values in the range $74-89 \%$, indicating clearly that these taxa belong to the same genospecies. Previous data by Ruiz-García et al. (2005) reported DNA-DNA relatedness values for $B$. velezensis $\mathrm{CR}-502^{\mathrm{T}}$ and B. amyloliquefaciens ATCC $23350^{\mathrm{T}}$ of $18.6 \%$, which is much lower than the value determined in our study. We presume that a mixed culture may possibly have been used in the DNA-DNA hybridization experiments of Ruiz-García et al. (2005). This kind of result was frequently reported by other taxonomists (Naser et al., 2006a, b; Kostinek et al., 2005; Wang et al., 2007a). The correlation between $g y r B$ gene sequence similarity values and levels of DNA-DNA relatedness in the species of the B. subtilis group were studied previously. Strains with approximately $95 \%$ or more gyrB gene sequence similarity in the cluster exhibited DNA-DNA relatedness of $>70 \%$, an acceptable value for proposal of a single species. The levels of $g y r B$ gene sequence similarity $(>95.5 \%)$ and DNA-DNA relatedness $(>74 \%)$ shared by $B$. velezensis BCRC $17467^{\mathrm{T}}$ and all B. amyloliquefaciens strains available indicated that they represent the same species in our previous study (Wang et al., 2007b).

Phenotypic features were investigated for $B$. velezensis BCRC $17467^{\mathrm{T}}$ and phylogenetically related species. Cellular fatty acid composition was determined according to the methods described by Tai et al. (2006). Their fatty acid compositions are listed in Supplementary Table S1 (available in IJSEM Online). B. velezensis BCRC $17467^{\mathrm{T}}$ and B. amyloliquefaciens BCRC 14193 showed similar fatty acid profiles, characterized mainly by their high $\mathrm{C}_{16: 0}$ fatty acid content, low anteiso- $\mathrm{C}_{17: 0}$ fatty acid content and the presence of $\mathrm{C}_{14: 0}$. However, fatty acid profiles have individual differences in all strains of B. amyloliquefaciens, indicating that these data are insufficient for species identification. Additional biochemical tests were performed using API 50CH and 20E (bioMérieux) following the manufacturer's instructions. Distinguishing biochemical characteristics are shown in Supplementary Table S2 (available in IJSEM Online). B. velezensis BCRC $17467^{\mathrm{T}}$ had few differences from $B$. amyloliquefaciens BCRC $11601^{\mathrm{T}}$ and other Bacillus strains. These species can be accurately differentiated from one another by DNADNA hybridization analysis, but it is quite difficult to distinguish members of the $B$. subtilis group by phenotypic characteristics.

Although the phenotypic characteristics have individual differences, these data are insufficient for species identification in the members of Bacillus closely related to the B. subtilis group, thus necessitating DNA-DNA hybridization tests. Based on the evidence from similarities of gyrB gene sequences and results from DNA-DNA hybridization studies, it is proposed that B. velezensis Ruiz-García et al. 2005 should be considered as a later heterotypic synonym of B. amyloliquefaciens Priest et al. 1987.

\section{Emended description of Bacillus amyloliquefaciens (ex Fukumoto 1943) Priest et al. 1987}

The description is the same as that given by Priest et al. (1987) except for the following traits. Catalase and oxidase are produced. Strains are capable of growing in $\mathrm{NaCl}$ concentrations up to $12 \% \mathrm{w} / \mathrm{v}$. Citrate utilization and Tween 20 hydrolysis are variable. They are able to produce dihydroxyacetone, but do not produce lecithinase. Acid is produced from aesculin, amygdalin, L-arabinose, arbutin, glycogen, inositol, lactose, methyl $\alpha$-D-glycoside, raffinose, D-ribose, salicin, sorbitol, starch, D-xylose, galactose and inulin. $\mathrm{H}_{2} \mathrm{~S}$ production and $\mathrm{ONPG}$ reaction are straindependent. Vogues-Proskauer test is positive. Tests for degradation of indole, lysine decarboxylase, ornithine decarboxylase, tryptophan deaminase and phenylalanine deaminase are negative. Major fatty acids are anteiso- $\mathrm{C}_{15: 0}$, iso- $\mathrm{C}_{15: 0}, \mathrm{C}_{16: 0}$, iso- $\mathrm{C}_{17: 0}$ and anteiso- $\mathrm{C}_{17: 0}$, according to this study and Ruiz-García et al. (2005). The DNA G+C content ranges from 44 to $46 \mathrm{~mol} \%$. Strains have been 
isolated from desert soils and brackish sediments. Additional chemotaxonomic data and biochemical tests are given in Supplementary Tables S1 and S2. The type strain is Fukumoto strain $\mathrm{F}^{\mathrm{T}}=\mathrm{ATCC} 23350^{\mathrm{T}}=\mathrm{DSM}$ $7^{\mathrm{T}}=\mathrm{BCRC} \quad 11601^{\mathrm{T}}=\mathrm{CIP} \quad 103265^{\mathrm{T}}=\mathrm{IFO} \quad($ now $\quad \mathrm{NBRC})$ $15535^{\mathrm{T}}=$ LMG $12234^{\mathrm{T}}=$ NCIMB $12077^{\mathrm{T}}=$ NRRL B-14393 ${ }^{\mathrm{T}}$.

\section{Acknowledgements}

We thank T. Y. Liu, C. C. Liao and G. F. Yuan (Food Industry Research and Development Institute, Taiwan) for their encouragement. This research was supported by the Taiwanese Ministry of Economic Affairs (project no. 95-EC-17 A-17-R7-0525).

\section{References}

Ezaki, T., Hashimoto, Y. \& Yabuuchi, E. (1989). Fluorometric deoxyribonucleic acid-deoxyribonucleic acid hybridization in microdilution wells as an alternative to membrane filter hybridization in which radioisotopes are used to determine genetic relatedness among bacterial strains. Int J Syst Bacteriol 39, 224-229.

Felsenstein, J. (2002). PHYLIP (Phylogeny Inference Package), version 3.6a. Distributed by the author. Department of Genome Sciences, University of Washington, Seattle, USA.

Fukumoto, J. (1943a). Studies on the production of bacterial amylase. I. Isolation of bacteria secreting potent amylase and their distribution. Nippon Nogei Kaggakai 19, 487-503 (in Japanese).

Fukumoto, J. (1943b). Studies on the production of bacterial amylase. II. Bacterial and physiological nature. Nippon Nogei Kaggakai 19, 643650 (in Japanese).

Goris, J., Suzuki, K., De Vos, P., Nakase, T. \& Kersters, K. (1998). Evaluation of a microplate DNA-DNA hybridization method compared with the initial renaturation method. Can J Microbiol 44, 1148-1153.

Harwood, C. R. (1992). Bacillus subtilis and its relatives: molecular biological and industrial workhorses. Trends Biotechnol 10, 247-256.

Kostinek, M., Pukall, R., Rooney, A. P., Schillinger, U., Hertel, C., Holzapfel, W. H. \& Franz, C. M. (2005). Lactobacillus arizonensis is a later heterotypic synonym of Lactobacillus plantarum. Int J Syst Evol Microbiol 55, 2485-2489.

Kumar, S., Tamura, K. \& Nei, M. (2004). MEGA3: integrated software for molecular evolutionary genetics analysis and sequence alignment. Brief Bioinform 5, 150-163.

Logan, N. A. \& Berkeley, R. C. (1984). Identification of Bacillus strains using the API system. J Gen Microbiol 130, 1871-1882.

Nakamura, L. K. (1987). Deoxyribonucleic acid relatedness of lactosepositive Bacillus subtilis strains and Bacillus amyloliquefaciens. Int Syst Bacteriol 37, 444-445.

Nakamura, L. K. (1989). Taxonomic relationship of black-pigmented Bacillus subtilis strains and a proposal for Bacillus atrophaeus sp. nov. Int J Syst Bacteriol 39, 295-300.

Nakamura, L. K., Roberts, M. S. \& Cohan, F. M. (1999). Relationship of Bacillus subtilis clades associated with strains 168 and W23: a proposal for Bacillus subtilis subsp. subtilis subsp. nov. and Bacillus subtilis subsp. spizizenii subsp. nov. Int J Syst Bacteriol 49, 1211-1215.
Naser, S. M., Hagen, K. E., Vancanneyt, M., Cleenwerck, I., Swings, J. \& Tompkins, T. A. (2006a). Lactobacillus suntoryeus Cachat and Priest 2005 is a later synonym of Lactobacillus helveticus (Orla-Jensen 1919) Bergey et al. 1925 (Approved Lists 1980). Int J Syst Evol Microbiol 56, 355-360.

Naser, S. M., Vancanneyt, M., Hoste, B., Snauwaert, C., Vandemeulebroecke, K. \& Swings, J. (2006b). Reclassification of Enterococcus flavescens Pompei et al. 1992 as a later synonym of Enterococcus casseliflavus (ex Vaughan et al. 1979) Collins et al. 1984 and Enterococcus saccharominimus Vancanneyt et al. 2004 as a later synonym of Enterococcus italicus Fortina et al. 2004. Int J Syst Evol Microbiol 56, 413-416.

O'Donnell, A. G., Norris, J. R., Berkeley, R. C. W., Kaneko, Logan, N. A. \& Nozaki, R. (1980). Characterization of Bacillus subtilis, Bacillus pumilus, Bacillus licheniformis, and Bacillus amyloliquefaciens by pyrolysis gas-liquid chromatography, deoxyribonucleic acid-deoxyribonucleic acid hybridization, biochemical tests, and API systems. Int J Syst Bacteriol 30, 448-459.

Priest, F. G. (1977). Extracellular enzyme synthesis in the genus Bacillus. Bacteriol Rev 41, 711-753.

Priest, F. G., Goodfellow, M., Shute, L. A. \& Berkeley, R. C. W. (1987). Bacillus amyloliquefaciens sp. nov., nom. rev. Int J Syst Bacteriol 37, 69-71.

Roberts, M. S., Nakamura, L. K. \& Cohan, F. M. (1994). Bacillus mojavensis sp. nov., distinguishable from Bacillus subtilis by sexual isolation, divergence in DNA sequence, and differences in fatty acid composition. Int J Syst Bacteriol 44, 256-264.

Roberts, M. S., Nakamura, L. K. \& Cohan, F. M. (1996). Bacillus vallismortis sp. nov., a close relative of Bacillus subtilis, isolated from soil in Death Valley, California. Int J Syst Bacteriol 46, 470-475.

Ruiz-García, C., Bejar, V., Martinez-Checa, F., Llamas, I. \& Quesada, E. (2005). Bacillus velezensis sp. nov., a surfactant-producing bacterium isolated from the river Vélez in Málaga, southern Spain. Int J Syst Evol Microbiol 55, 191-195.

Skerman, V. B. D., McGowan, V. \& Sneath, P. H. A. (editors) (1980). Approved lists of bacterial names. Int J Syst Bacteriol 30, 225-420.

Tai, C. J., Kuo, H. P., Lee, F. L., Chen, H. K., Yokota, A. \& Lo, C. C. (2006). Chryseobacterium taiwanense sp. nov., isolated from soil in Taiwan. Int J Syst Evol Microbiol 56, 1771-1776.

Tamaoka, J. \& Komagata, K. (1984). Determination of DNA base composition by reversed-phase high performance liquid chromatography. FEMS Microbiol Lett 25, 125-128.

Thompson, J. D., Gibson, T. J., Plewniak, F., Jeanmougin, F. \& Higgins, D. G. (1997). The CLUSTAL_X windows interface: flexible strategies for multiple sequence alignment aided by quality analysis tools. Nucleic Acids Res 25, 4876-4882.

Wang, L. T., Lee, F. L., Tai, C. J., Yokota, A. \& Kuo, H. P. (2007a). Reclassification of Bacillus axarquiensis Ruiz-García et al. 2005 and Bacillus malacitensis Ruiz-García et al. 2005 as later heterotypic synonyms of Bacillus mojavensis Roberts et al. 1994. Int J Syst Evol Microbiol 57, 1663-1667.

Wang, L. T., Lee, F. L., Tai, C. J. \& Kasai, H. (2007b). Comparison of gyrB gene sequences, 16S rRNA gene sequences and DNA-DNA hybridization in the Bacillus subtilis group. Int J Syst Evol Microbiol 57, 1846-1850. 